\title{
Homosexual Pairing within a Swarm-Based Mating System: The Case of the Chironomid Midge
}

\author{
Athol J. McLachlan \\ School of Biology, Newcastle University, Newcastle upon Tyne NE1 7RU, UK \\ Correspondence should be addressed to Athol J. McLachlan, a.j.mclachlan@virgin.net \\ Received 10 May 2011; Revised 7 July 2011; Accepted 10 August 2011 \\ Academic Editor: Carlos Cordero \\ Copyright () 2011 Athol J. McLachlan. This is an open access article distributed under the Creative Commons Attribution License, \\ which permits unrestricted use, distribution, and reproduction in any medium, provided the original work is properly cited. \\ Homosexuality has been dubbed the Darwinian paradox, because it raises the question of how behaviour that would seem to \\ reduce the chance of successful mating can be maintained by natural selection. This question rests on the assumption that same \\ sex mating is the result of active choice of partner, hardwired into the mating behaviour, but there is an alternative explanation for \\ such behaviour. I refer to the possibility that same-sex mating is the result, not of adaptive behaviour at all, but rather of errors due \\ to imprecise sensory machinery. Such an explanation finds support within the mating system of insects with swarm-based mating \\ systems. To explore this case, I turn to the common chironomid midge. I show that homosexual pairing here, exclusively involving \\ male/male pairs, is common. I attempt to show that this observation, together with data on insect predators of swarming midges, \\ can be used to penetrate the mysteries of this fascinating but elusive mating system.
}

\section{Introduction}

Anomalous mating is currently attracting intense interest (e.g., see [1]). It is a phenomenon widely observed among animals, having been recorded at high frequencies in both vertebrates and invertebrates. It is anomalous behaviour because it would seem to reduce the chance of producing offspring and hence reduces fitness, so should not be favoured by natural selection. This is the so-called Darwinian paradox (e.g., see [2]). However, close inspection of specific cases show that the fitness of homosexual individuals, usually males, can actually be improved by such behaviour. For example, the well-documented case of homosexual pairing in garter snakes suggests that such homosexual behaviour, that is, males that behave like females, can carry fitness benefits for subordinate males [3]. In other words, homosexual mating can have evolved as an alternative mating tactic, favoured by selection within an evolutionarily stable strategy (ESS) [4]. However, though an interesting idea, there has been some question raised over the evidence for ESS in the wild [5]. So, the possibility that such behaviour is not an adaptation at all but simply a flexible response to poor condition during development resulting in weak phenotypes must be considered. In this context, environmental stress during development might produce males which cannot compete directly with alpha males and thus have lower fitness that rivals. This line of reasoning still leaves the question of the evolutionary origin of female like behaviour. One possibility is that homosexual males find their origin in cross-sexual transfer. That is, where characters normally expressed in one sex, the females, appear in the male [5]. Fairbairn [6] emphasises another possible adaptive scenario, especially relevant to humans. I refer to what has been called sexually antagonistic selection [7], which results in genetic conflict if the traits are determined by the same genes in both sexes. She suggests that while reducing fitness in sons, interlocus conflict can lead to compensating benefits for daughters. Thus, since there can be gains in fitness through homosexual behaviour, the seeming paradox can be circumvented. The matter of homosexuality in humans is further discussed by Dawkins ([8, pages 37-38]).

Among invertebrates, it is the insects that have received the most attention and in many of these, mate choice falls to the male rather than the female, though the matter is not straight forward [9]. This is unusual, as orthodoxy predicts that the female should be the one to choose and there 
is a massive body of evidence that this is often the case, especially among birds and mammals [10]. The matter of choice by the male has many interesting twists. For example, Thornhill and Alcock [11] show that mate choice behaviour in the males of many insect species is not precisely tuned to detecting females. Rather, it is imprecise and can lead to errors. They provide the example of an unnamed buprestid beetle attempting to mate with a bottle, presumably because the bottle possesses some of the visual properties of a mate, perhaps to a supranormal degree and may thus be especially attractive to the male. It is this promiscuous mating behaviour that has been exploited by the orchids [11], where a slight resemblance to a female insect is evidently sufficient to provoke mating attempts leading to pollination. Indeed mistakes in mate choice in many insects may be due to selection favouring imprecise sexual discrimination behaviour. Thornhill and Alcock ([11, page 134]) provide an interesting thought experiment to show that such a promiscuous system might carry fitness advantages over a more finely-tuned one.

Throughout this paper I use the term "choice" in the general sense of West-Eberhard [5, page 442], that is, "Choice between two or more actions. . .or individuals occurs when there is a differential response to stimulus difference associated with the alternatives..." This is in accordance with the more specific definition of Bonduriansky [12]. A more precise definition of what is meant by "choice" in midge swarms is that the male is able to differentiate between what is male and what is female. This is somewhat different for males choosing a female for an array of those available. I see this, not as something new, but rather as a special case of "choice."

\section{Swarm-Based Mating Systems}

Swarm-based mating systems typically involve males flying in swarms to attract patrolling females. Such swarms are often on immense size (Figure 1).

Swarm-based mating systems are widespread among insects, being recorded among beetles, termites, dragonflies, bees, ants, caddis flies, stone flies, mayflies, and among the true flies (Diptera) in Trichoceridae, Empididae, Culicidae, Ceratopogonidae, Simulidae, Chaoboridae, Bibionidae, and Chironomidae [13]. These swarms are essentially leksassemblages of males that offer nothing to mates but their genes. Leks have been much studied among the vertebrates, especially birds, where choice by the female is central to the system [9]. Invertebrate leks cry out for attention [14]. Central to the study of the lek is another paradox which arises from the expectation that females should choose males of high genetic quality as advertised by the quality of the display [15]. There are several layers to this paradox but ultimately depletion of the genetical variability upon which natural selection depends would be expected and adaptive change might eventually come to a halt. There are solutions to this seeming paradox, of course, which I do not here pursue, but see $[16,17]$.

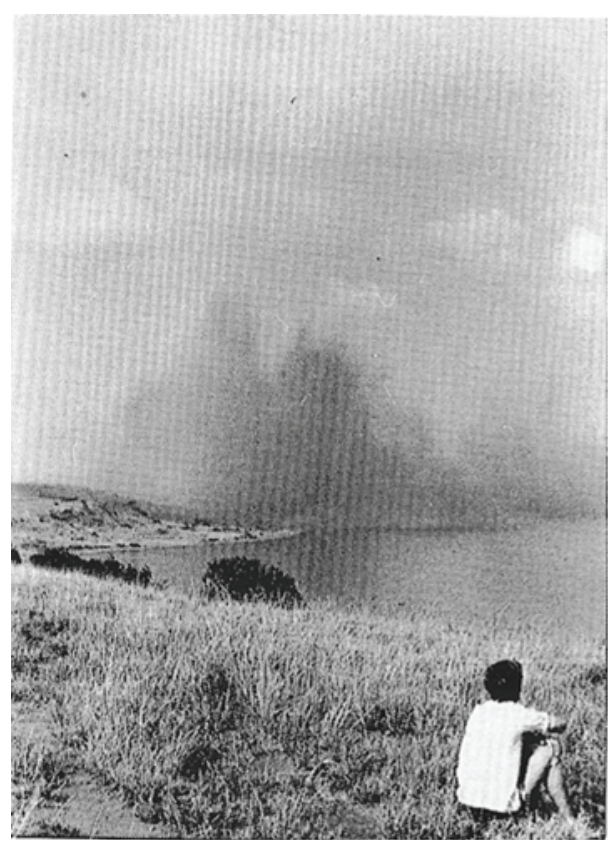

Figure 1: A swarm of chaoborid midges over Lake George, Uganda (photo by L. McGowan).

\section{Anomalous Pairing among Chironomid Midges}

The swarm-based mating system of chironomids poses several unresolved questions. Principal among them is the matter of how a pairing is actually achieved. This simple question has consumed much research effort [18]. I attempt here to show that the occurrence of same-sex pairs helps resolve this central question. In the end, the available evidence suggests that the homosexual pairs observed in chironomid swarms are due to mistakes of the kind described by Thornhill and Alcock [11]. The findings from a sampling programme running over two sampling season is shown in Table 1.

This data reveals some trends. The most interesting of these, in the context of homosexual pairing, is the high frequency at which male/male pairs form. Indeed, homosexual pairs are often the only ones captured on an evening's sampling, perhaps because there were no females available on the evening. By contrast, homosexual pairs of females were recorded only once over the entire two-year period. At first sight this observation concerning female homosexual pairs might seem highly significant and lead to adaptive conjecture. However, put into the context of the mating swarm the explanation is obvious. Male swarms of a common and iconic chironomid midge, Chironomus plumosus, typically number about four thousand individuals [20], which is probably fairly typical for chironomids [21]. Females enter the swarm briefly in ones or twos and hence represent a rare and transient event. Hence the absence of female/female pairs is not surprising. Indeed, the presence of even one is noteworthy. What is more interesting is a comparison between male/male pairs and male/females pairs. 
TABle 1: Number of pairs, in various categories, captured from mating swarms of the midge Chironomus plumosus, on twenty evenings during 1994 and 1995. The first column assigns code numbers to the occasions. a, male/male pairs. b, female/female pairs. c, male/empid pairs. d, male/female pairs. From primary data of McLachlan [19].

\begin{tabular}{|c|c|c|c|c|}
\hline Date & $\begin{array}{c}a \\
0^{7} / 0^{x}\end{array}$ & $\begin{array}{c}\mathrm{b} \\
9 / \%\end{array}$ & $\begin{array}{c}c \\
\sigma^{x} / e^{2} \text { pid }\end{array}$ & $\begin{array}{c}\mathrm{d} \\
\sigma^{7} / q\end{array}$ \\
\hline (1) $11 / 5 / 1994$ & 8 & 1 & 0 & 0 \\
\hline (2) $25 / 5 / 1994$ & 2 & 0 & 0 & 0 \\
\hline (3) $02 / 6 / 1994$ & 11 & 0 & 1 & 0 \\
\hline (4) $06 / 6 / 1994$ & 2 & 0 & 0 & 3 \\
\hline (5) $13 / 6 / 1994$ & 1 & 0 & 1 & 12 \\
\hline (6) $14 / 6 / 1994$ & 2 & 0 & 0 & 2 \\
\hline (7) $22 / 5 / 1995$ & 5 & 0 & 0 & 17 \\
\hline (8) $23 / 05 / 1995$ & 7 & 0 & 0 & 5 \\
\hline (9) $24 / 5 / 1995$ & 7 & 0 & 3 & 12 \\
\hline (10) $25 / 5 / 1995$ & 1 & 0 & 5 & 0 \\
\hline (11) 30/5/1995 & 3 & 0 & 1 & 1 \\
\hline (12) $31 / 5 / 1995$ & 2 & 0 & 2 & 0 \\
\hline (13) 05/6/1995 & 1 & 0 & 3 & 0 \\
\hline (14) 8/6/1995 & 1 & 0 & 3 & 0 \\
\hline (15) $12 / 6 / 1995$ & 0 & 0 & 0 & 1 \\
\hline (16) $13 / 6 / 1995$ & 2 & 0 & 0 & 9 \\
\hline (17) $15 / 6 / 1995$ & 1 & 0 & 0 & 10 \\
\hline (18) $16 / 6 / 1995$ & 0 & 0 & 4 & 5 \\
\hline 20/6/1995 (19) & 0 & 0 & 0 & 2 \\
\hline (20) $21 / 6 / 1995$ & 0 & 0 & 0 & 1 \\
\hline Total & 56 & 1 & 23 & 80 \\
\hline
\end{tabular}

The creation of the male/female is, after all, the function of the swarm. Despite the overwhelming likelihood of any male encountering another male in a swarm, males paired with females are, on the average, strongly predominant A total of $56 \mathrm{male} / \mathrm{male}$ pairs were captured over the sampling period compared with 80 male/female pairs (i.e., close to $60 \%$ of all pairs were male/female). In view of the temporal scarcity of females this finding suggests a fine-tuned female detection ability in males where homosexual pairing can be seen as a mistake made by eager males in an intense scramble competition [10]. So, it is difficult to avoid the conclusion that the mating system hinges on the male rather than the female, but as already pointed out, this is not quite the same as "male choice" in the sense of [12].

A heterogeneity $X_{0.05,1}^{2}$ test in a $2 \times 2$ contingency table [22] prohibits the pooling of sampling occasions. Taking occasion separately and adopting the method of Thomas et al. [23], Table 2 shows that, despite strongly male-biased sex ratio within a mating swarm, on occasion $5,16,17$, and $18 \mathrm{male} / \mathrm{female}$ pairs dominate over male/male pairs. Only on occasions 1,2 , and 10 do male/male pairs significantly predominate (i.e., $X_{0.05,1}^{2} . P<0.05$ in both cases).

The proximate cause of pairing appears to be the sound emitted by the wing beats of the females that the male uses as
TABle 2: $X_{0.05,1}^{2}, 2 \times 2$ contingency table to illustrate the statistical method adopted. This example is for pooled data to test the null hypothesis that there is no difference between columns.

\begin{tabular}{lccc}
\hline & \multicolumn{2}{c}{ Pairs } \\
& Male/male & Male/female \\
\hline observed & 56 & 80 \\
expected & 68 & 68 \\
\hline
\end{tabular}

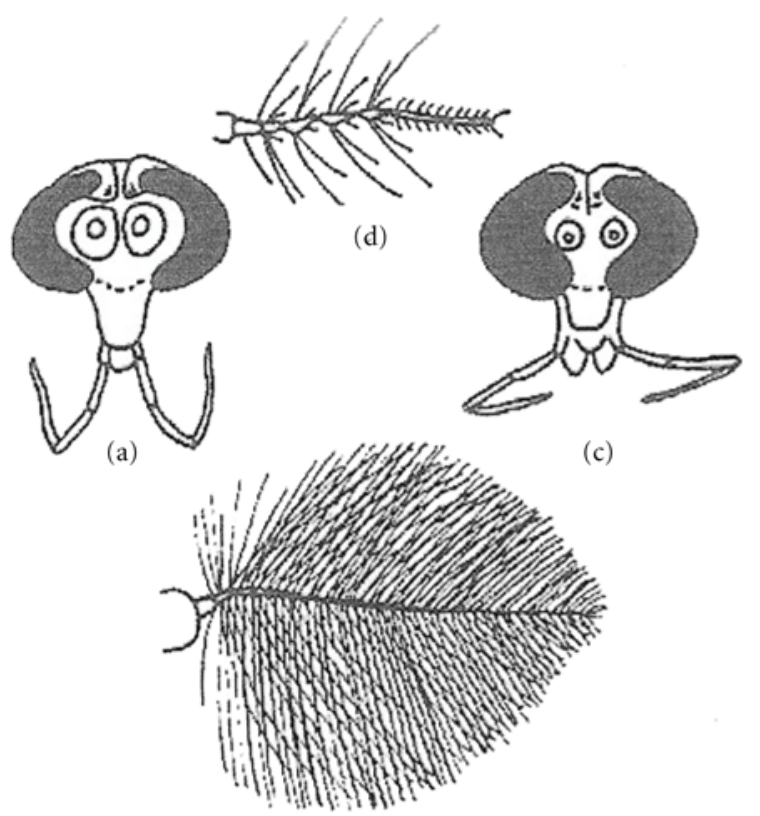

(b)

FIGURE 2: The sensory equipment of the chironomid midge. Front view of head of male (a) and antenna (b); (c) and (d) the same for the female. (Modified after [24], with permission).

his primary cue, rather than sight. The complex antennae of the male are thought to be the principal sense organ involved [13] (Figure 2).

Although motor indicators such as these are thought to be more reliable as cues than visual ones [25], wing beat sound, I suggest, is a fallible cue as it may be prone to changes as the female manoeuvres within the male swarm and this may be a proximate reason for the mistakes made by males. In this regard, a research programme to investigate wing beat sound within the swarm could be rewarding. Mosquitoes adopt a similar mating system to that of chironomid midges and research on the mating system of mosquitoes has lead independently to a similar conclusion regarding the role of sound in mate detection [26].

I have one other piece of evidence that helps unravel the complexities of the chironomid mating system. I refer to a predator of midge mating swarms, the empid fly Empis stercorea which, I suggest, may be sufficiently common as a predator to be one of the selective forces shaping the mating system of the midge. Comparing columns a and c in Table 1 shows empids to be regularly successful at capturing male midges. A comparison of column $\mathrm{c}$ and $\mathrm{d}$ in Table 1 suggests 


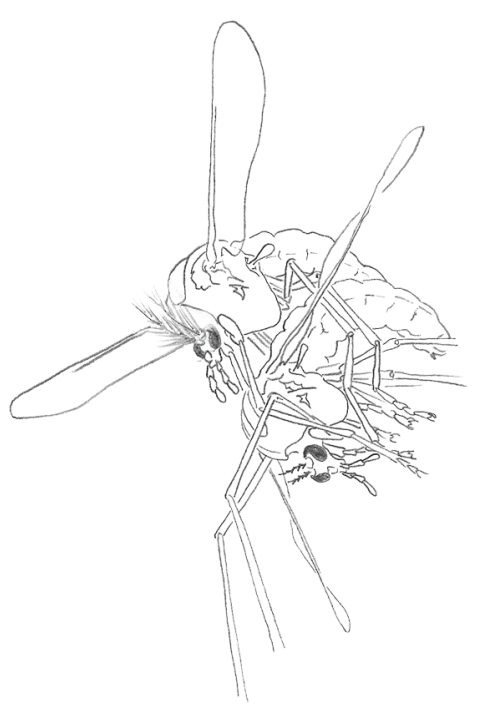

Figure 3: A male/female mating pair of chironomid midges (Chironomus plumosus). The male, with plumose antennae, grasps the female, below. Wing length c. 2 mm (drawing by B. Compton).

that male midges may be more successful at capturing the rare female than empids are at capturing the abundant male midges. This comparison is made leaving aside all zeros, that is, occasions when there may have been no empids and/or female midges. I make the assumption too, that the numbers of females and of empids in the swarm at any one time are approximately the same. This assumption is reasonable but awaits confirmation. The performance of the empid may be telling us something interesting about the relative efficiency of male chironomids and of empids at capturing their "prey." More work is needed here.

This predacious fly is so like a female chironomid, in general appearance in flight, as to confuse the human observer and possibly the male midge as well [27]. If the male mistakes an empid for a partner, the job of the predator is made that much easier. I do not suggest that the male actually grasps the empid but rather that he may approach close enough to be grasped by it. Both the comparison between the success of males at capturing females and of empids at capturing males lend support to the conclusion that the chironomid mating system hinges on choice by the male midge pursuing fleeing females.

$X_{0.05,20}^{2}$ heterogeneity tests prohibit the pooling of data in both comparisons involving empids, that is, a versus $c$ and $c$ versus $d$. Taking $c$ versus $d$ first and treating sampling occasions separately shows male/female midge pairs to be significantly more frequent than male/empid pairs on occasions $5,7,8,9,16$, and 17 . Only on occasion 18 do empid/male pairs predominate significantly. Comparing $\mathrm{a}$ and $\mathrm{c}, \mathrm{a}$ is at a significantly higher frequency that $\mathrm{c}$ on occasions $1,3,7$, and 8 (Table 1 ).

Figure 3 shows a typical male/female pair of chironomid midges as would be seen emerging from a mating swarm. The pair stays together for a few seconds and can be captured as they alight on a sheet spread below the swarm, for example, [28].

\section{Conclusions}

I here use the presence of homosexual pairs of males at high frequency in a swarm-based mating system in an attempt to understand this type of system. For the specific case of the illusive mating system of the common chironomid midge, the conclusion I reach is that this system is coercion driven with male midges in pursuit of fleeing females $[29,30]$. This conclusion finds support both in a comparison of male/male midge pairs with males in pairs with an empid predator and with pairs of males with female midges.

The midge mating system has several interesting biomechanical and sensory features $[12,13]$, but it received relatively little attention and would reward further work. This is a suggestion made feasible by the development of high-speed video recording equipment which is revealing many secrets previously hidden from observation (e.g., [31]).

\section{Acknowledgment}

The author acknowledges the perceptive comments of an editor and an unnamed referee.

\section{References}

[1] A. Poiani, Animal Homosexuality: A Biosocial Approach, Cambridge University Press, Cambridge, UK, 2011.

[2] S. Bedhomme and A. K. Chippindale, "Irreconcilable differences: when sexual dimorphism fails to resolve sexual conflict," in Sex, Size, and Gender Roles: Evolutonary Studies of sexual Size Dimorphism, D. J. Fairbairn, W. U. Blackenhorn, and T. Szekely, Eds., Oxford University Press, Oxford, UK, 2007.

[3] R. T. Mason and D. Crews, "Female mimicry in garter snakes," Nature, vol. 316, no. 6023, pp. 59-60, 1985.

[4] G. A. Parker, "Evolutionarily stable strategies," in Behavioural Ecology: An Evolutionary Approach, J. R. Krebs and N. B. Davies, Eds., Blackwell Scientific Publications, Oxford, UK, 1984.

[5] M. J. West-Eberhard, Developmental Plasitcity and Evolution, Oxford University Press, Oxford, UK, 2003.

[6] D. J. Fairbairn, W. U. Blackenhorn, and T. Székely, Eds., Sex, Size and Gender Roles: Evolutionary Studies of Sexual Size Dimorphism, Oxford University Press, Oxford, UK, 2007.

[7] R. Bonduriansky and S. F. Chenoweth, "Intralocus sexual conflict," Trends in Ecology and Evolution, vol. 24, no. 5, pp. 280-288, 2009.

[8] R. Dawkins, The Extended Phenotype, Oxford University Press, Oxford, UK, 1999.

[9] N. W. Bailey and M. Zuk, "Same-sex sexual behavior and evolution," Trends in Ecology and Evolution, vol. 24, no. 8, pp. 439-446, 2009.

[10] J. R. Krebs and Davies N. B., An Introduction to Behavioural Ecology, Blackwell Scientific Publications, London, UK, 1981.

[11] R. Thornhill and J. Alcock, The Evolution of Insect Mating Systems, Harvard University Press, London, UK, 1983.

[12] R. Bonduriansky, "The evolution of male mate choice in insects: a synthesis of ideas and evidence," Biological Reviews of the Cambridge Philosophical Society, vol. 76, no. 3, pp. 305339, 2001. 
[13] A. J. McLachlan and Neems R. M., "Swarm based mating sysems," in Insect Reproduction, S. R. Leather and J. Hardie, Eds., CRC Press, New York, NY, USA, 1995.

[14] J. W. Bradbury and N. B. Davies, "Relative roles of intraand intersexual selection," in Sexual Selection: Testing the Alternatives, J. W. Bradbury and N. B. Davies, Eds., John Wiley \& Sons, New York, NY, USA, 1987.

[15] G. Borgia, "Sexual selection and the evolution of mating systems," in Selection and Reproductive Competition in Insects, M. S. Blum and N. A. Blum, Eds., Academic Press, New York, NY, USA, 1979.

[16] R. J. Knell and L. W. Simmons, "Mating tactics determine patterns of condition dependence in a dimorphic horned beetle," Proceedings of the Royal Society B, vol. 277, no. 1692, pp. 2347-2353, 2010.

[17] J. Roughgarden and E. Akçay, "Do we need a Sexual Selection 2.0?" Animal Behaviour, vol. 79, no. 3, pp. e1-e4, 2010.

[18] B. Crompton, J. C. Thomason, and A. McLachlan, "Mating in a viscous universe: the race is to the agile, not to the swift," Proceedings of the Royal Society B, vol. 270, no. 1528, pp. 19911995, 2003.

[19] A. J. McLachlan, "Size or symmetry: an experiment to determine which of the two accounts for mating success in male midges," Ecoscience, vol. 4, no. 4, pp. 454-459, 1997.

[20] R. M. Neems, J. Lazarus, and A. J. Mclachlan, "Swarming behavior in male chironomid midges: a cost-benefit analysis," Behavioral Ecology, vol. 3, no. 4, pp. 285-290, 1992.

[21] J. A. Downes, "The swarming and mating flight of Diptera," Annual Review of Entomology, vol. 14, pp. 171-297, 1969.

[22] J. H. Zar, Biostatistical Analysis, Prentice Hall, London, UK, 1974.

[23] F. Thomas, F. Renaud, and F. Cezilly, "Assortative pairing by parasitic prevalence in Gammarus insensibilis (Amphipoda): patterns and processes," Animal Behaviour, vol. 52, no. 4, pp. 683-690, 1996.

[24] P. Freeman, "A study of the Chironomidae (Diptera) of Africa South of the Sahara," The Bulletin of the British Museum, vol. 4, pp. 1-69, 1955.

[25] J. Byers, E. Hebets, and J. Podos, "Female mate choice based upon male motor performance," Animal Behaviour, vol. 79, no. 4, pp. 771-778, 2010.

[26] L. J. Cator, K. R. Ng'Habi, R. R. Hoy, and L. C. Harrington, "Sizing up a mate: variation in production and response to acoustic signals in Anopheles gambiae," Behavioral Ecology, vol. 21, no. 5, pp. 1033-1039, 2010.

[27] A. McLachlan, R. Ladle, and B. Crompton, "Predator-prey interactions on the wing: aerobatics and body size among dance flies and midges," Animal Behaviour, vol. 66, no. 5, pp. 911-915, 2003.

[28] A. McLachlan, "Parasites promote mating success: the case of a midge and a mite," Animal Behaviour, vol. 57, no. 6, pp. 1199 1205, 1999.

[29] T. Tregenza, N. Wedell, and T. Chapman, "Introduction. Sexual conflict: a new paradigm?” Philosophical Transactions of the Royal Society B, vol. 361, no. 1466, pp. 229-234, 2006.

[30] A. J. McLachlan, T. W. Pike, and J. C. Thomason, "Another kind of symmetry: are there adaptive benefits to the arrangement of mites on an insect host?" Ethology Ecology and Evolution, vol. 20, no. 3, pp. 257-270, 2008.

[31] L. Buchen, "Flies on film," Nature, vol. 462, no. 7273, pp. 562564, 2009. 

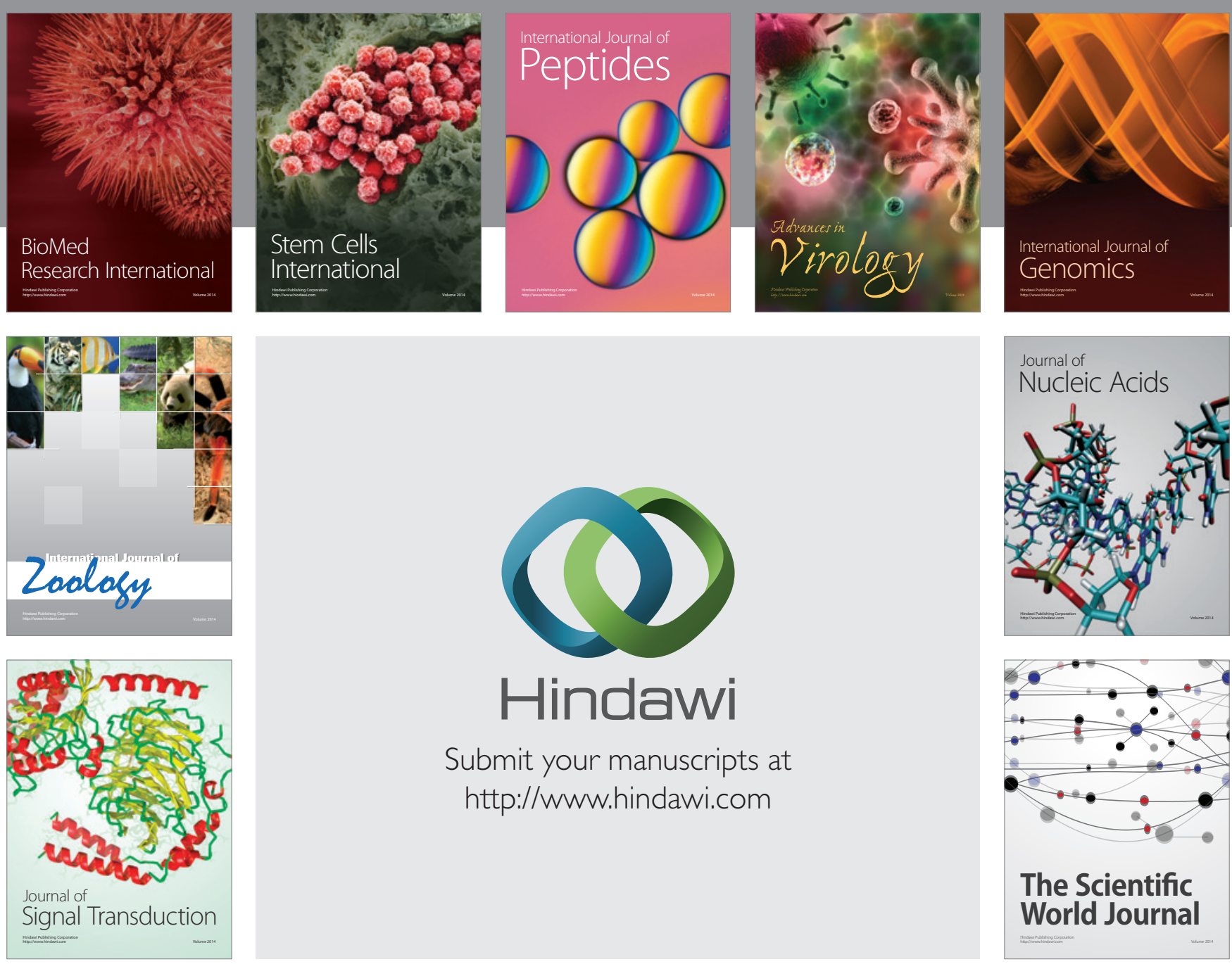

Submit your manuscripts at

http://www.hindawi.com
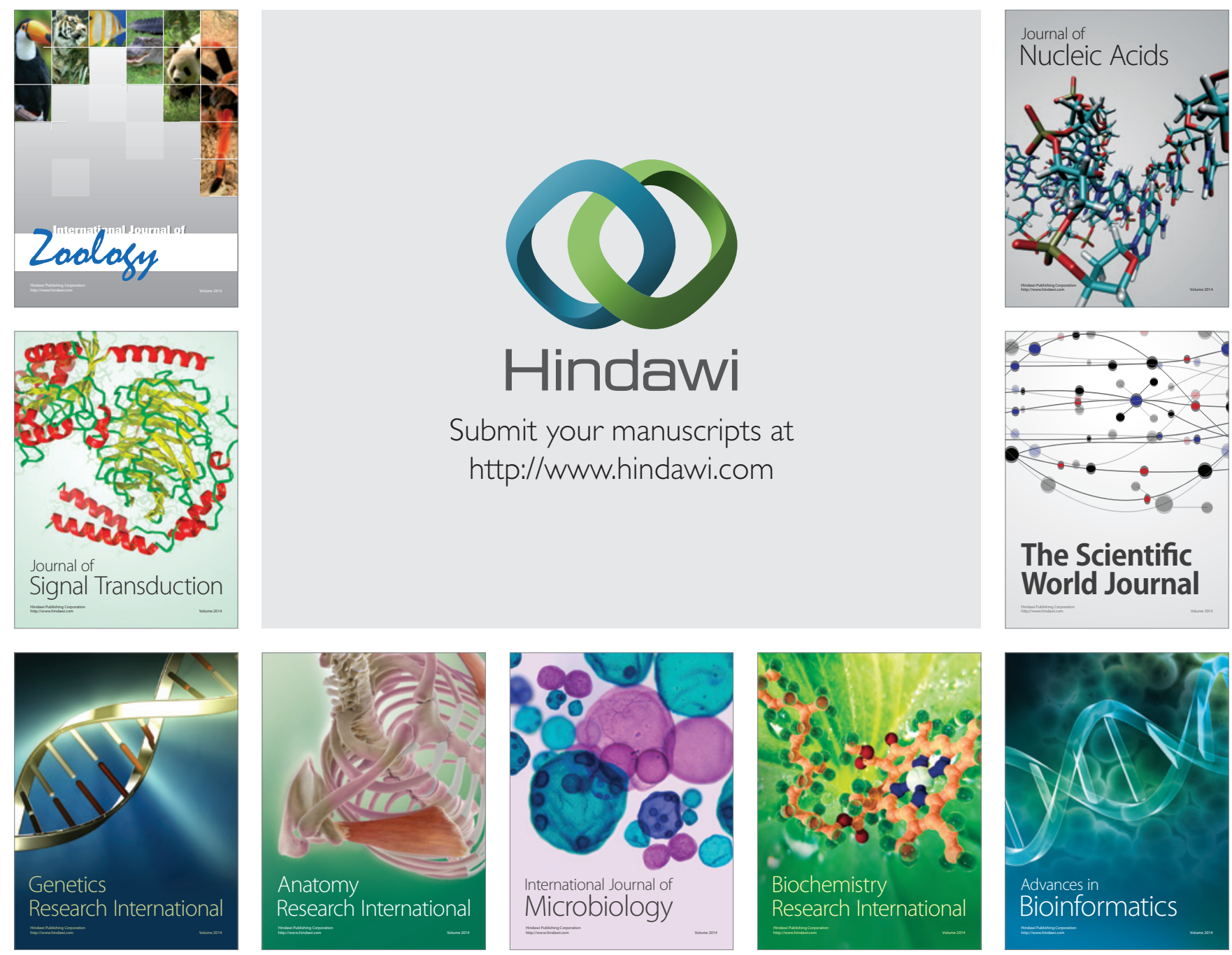

The Scientific World Journal
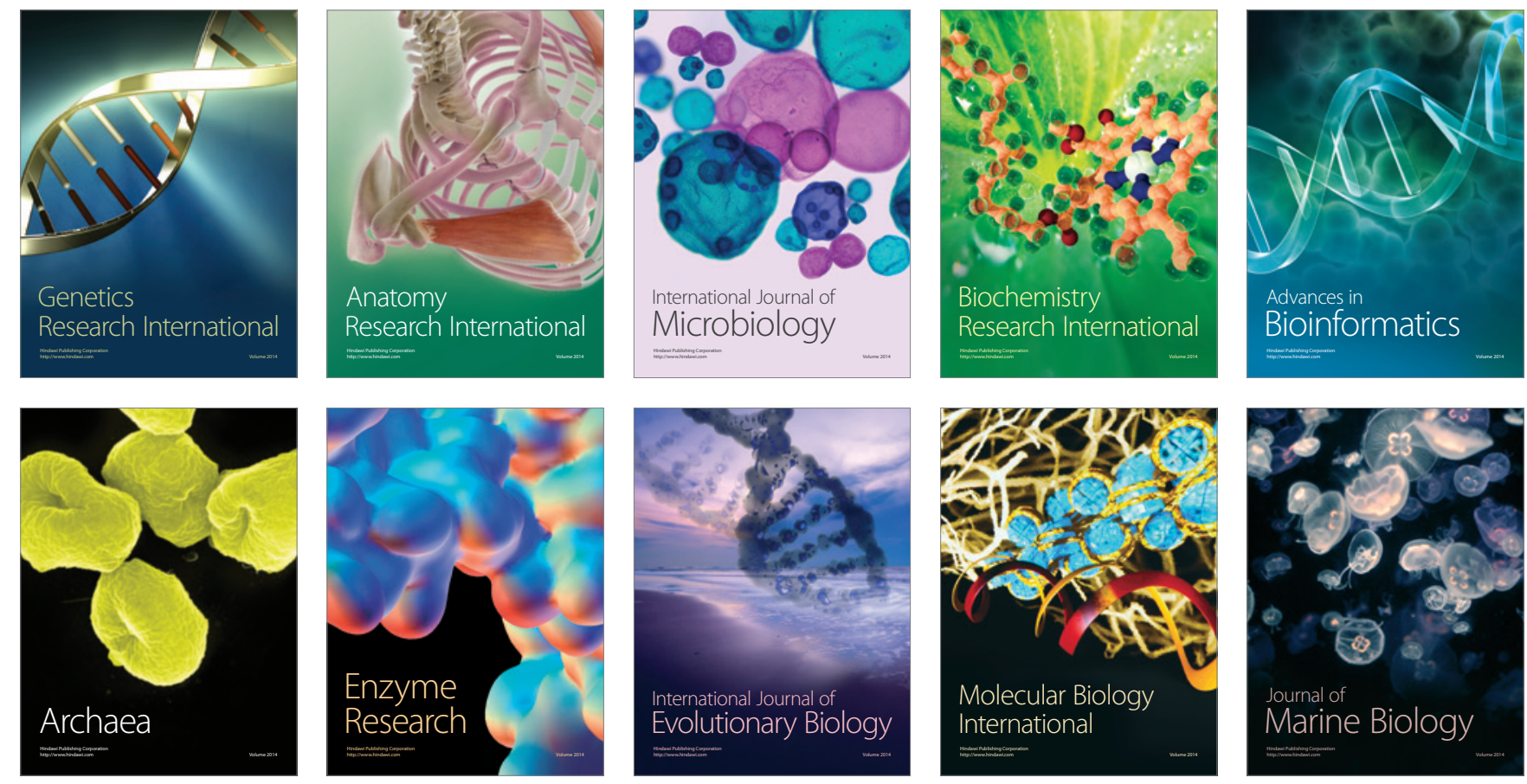